Article

\title{
Mortality Rate and Predictors of Mortality in Hospitalized COVID-19 Patients with Diabetes
}

\author{
Dilaram Acharya ${ }^{1,2} \mathbb{1}$, Kwan Lee ${ }^{1}\left(\mathbb{D}\right.$, Dong Seok Lee ${ }^{3}$, Yun Sik Lee ${ }^{4}$ and Seong-Su Moon ${ }^{5, *}$ \\ 1 Department of Preventive Medicine, College of Medicine, Dongguk University, Gyeongju 38066, Korea; \\ dilaramacharya123@gmail.com (D.A.); kwaniya@dongguk.ac.kr (K.L.) \\ 2 Department of Community Medicine, Kathmandu University, Devdaha Medical College and Research \\ Institute, Rupandehi 32900, Nepal \\ 3 Department of Pediatrics, Dongguk University College of Medicine, Gyeongju 38067, Korea; \\ lds117@dongguk.ac.kr \\ 4 Department of General Surgery, Andong Medical Center, Andong 36694, Korea; ysleewmbh@hanmail.net \\ 5 Department of Internal Medicine, Dongguk University College of Medicine, Dongguk University Gyeongju \\ hospital, Dongdae-ro 87, Gyeongju 38067, Korea \\ * Correspondence: drmoonss@hanmail.net
}

Received: 1 September 2020; Accepted: 11 September 2020; Published: 13 September 2020

\begin{abstract}
Studies have confirmed COVID-19 patients with diabetes are at higher risk of mortality than their non-diabetic counterparts. However, data-driven evidence of factors associated with increased mortality risk among hospitalized COVID-19 patients with diabetes is scarce in South Korea. This study was conducted to determine the mortality rate and identify risk factors of mortality among hospitalized COVID-19 patients with type 2 diabetes in Gyeongsangbuk-do province, South Korea. In this hospital-based, cross-sectional study, we enrolled a total of 324 patients with confirmed COVID-19, hospitalized at two of the tertiary level healthcare facilitates of Gyeongsangbuk-do, South Korea from 18 February to 30 June 2020. Demographic and clinical data and laboratory profiles were analyzed and multivariate logistic regression analysis was used to identify risk factors of mortality among diabetic patients with COVID-19. Of the 324 patients, 55 (16.97\%) had diabetes mellitus. The mean age of all study subjects was 55 years, and the mean age of those with diabetes was greater than that of those without (69.8 years vs. 51.9 years). Remarkably, the mortality rate was much higher among those with diabetes (20.0\% vs. $4.8 \%)$. Multivariate logistic regression analysis revealed that an older age ( $\geq 70$ years) and a high serum lactate dehydrogenase (LDH) levels significantly predicted mortality among hospitalized COVID-19 patients with diabetes. Our study cautions more attention to be paid to patients with diabetes mellitus hospitalized for COVID-19, especially those aged $\geq 70$ years and those with a high serum LDH level, to reduce the risk of mortality.
\end{abstract}

Keywords: coronavirus; diabetes; mortality; pandemics; Korea

\section{Introduction}

Severe acute respiratory syndrome coronavirus-2 (SARS-CoV-2) first emerged in Wuhan, China, in late 2019 and has since reached pandemic proportions, caused 646,000 deaths, and resulted in more than 16 million cases of COVID-19 as of 27 July 2020 [1]. In South Korea, 13,007 confirmed cases, and a total of 300 deaths were reported as of 28 July [2]. In addition to its devastating effects on health, the virus has caused severe economic disruption, and thus, has markedly reduced quality of life worldwide [3-6]. It would seem that the COVID-19 pandemic is set to continue until game-changers like an effective vaccine and or therapy appear [7]. Infections are difficult to manage, and mortality rates are likely to increase until a viable vaccine or chemotherapeutic becomes available. Until then we 
are obliged to rely on preventive measures that have proven to be effective, such as wearing masks, washing hands frequently, maintaining social distance, contact tracing, and testing [6,8,9].

Comorbid conditions such as diabetes mellitus, respiratory, cardiovascular and renal illnesses, and obesity, and an older age group are known to be positively associated with poor outcomes among COVID-19 patients [10-13]. Furthermore, research studies have demonstrated that COVID-19 patients with diabetes have poorer clinical prognoses, are at higher risks of complications, such as respiratory failure and acute cardiac injury, and have shorter overall survival times than their non-diabetic counterparts [14].

Several systematic reviews and meta-analyses [15,16], cohort [14,17], case-control [12], and cross-sectional studies [16,18] have demonstrated that diabetic patients with COVID-19 are at considerably greater risk of mortality and of developing more severe disease than COVID-19 patients without diabetes. However, it was reported in a recent study that diabetes had no effect on the prognosis of COVID-19 patients but was negatively associated with clinical outcomes [19], which indicated studies are needed to narrow gaps in our understanding of the disease, and thus, aid decision-making by health care providers and administrators. Given the current level of understanding of COVID-19 knowledge, we undertook to determine the additional risk posed by COVID19 to diabetic patients, to document mortality rates, and identify risk factors of mortality among COVID-19 patients with type 2 diabetes hospitalized in Gyeongsangbuk-do province, South Korea.

\section{Materials and Methods}

\subsection{Study Design and Subjects}

Three hundred and twenty-four patients (135 males and 189 females) with a diagnosis of COVID-19, hospitalized in Dongguk University Gyeongju Hospital (DUGH) or Andong Medical Center (AMC), Gyeongsangbuk-do, Korea from 18 February to 30 June 2020, were enrolled in this cross-sectional study. Patients re-hospitalized due to a positive RT-PCR result after discharge or were still in hospital were excluded. Only initial AMC records of patients transferred from AMC to DUGH were included. Demographic and clinical characteristics, including chest radiologic (X-ray or computerized tomography (CT) and laboratory findings, were collated. Laboratory blood analysis was performed at time of admission and included blood glucose, complete blood cell (CBC) counts, aspartate aminotransferase (AST), alanine aminotransferase (ALT), glycosylated hemoglobin $(\mathrm{HbA1c})$, lactate dehydrogenase (LDH), blood urea nitrogen $(\mathrm{BUN})$ and creatinine levels, albumin, and C-reactive protein (CRP). Therapeutics administered included lopinavir/ritonavir, chloroquine, antibiotics, macrolide, pegylated interferon- $\alpha$, and oxygen supplementation.

\subsection{Statistical Analysis}

Nominal variables are presented as numbers of cases and percentages, and continuous variables as means and standard deviations (SDs). The student's $t$-test or the Mann-Whitney U test was used to determine the significances of differences between two groups (Diabetes vs. Non-diabetes), and Chi-square analysis or Fisher's exact test was used to determine the significances of differences between categorical variables. Deaths included patients that had expired after transfer to another hospital. Laboratory parameters were classified as 'above normal limit', 'normal' or 'below normal limit' based on reference ranges, as follows; high AST, $>39 \mathrm{U} / \mathrm{L}$ (male) and $>31 \mathrm{U} / \mathrm{L}$ (female); high ALT, $>40 \mathrm{U} / \mathrm{L}$ (male) and >32 U/L (female); high LDH, $>225 \mathrm{U} / \mathrm{L}$ (male) and >214 U/L (female); high creatinine, $1.3 \mathrm{mg} / \mathrm{dL}$ (male) and $1.1 \mathrm{mg} / \mathrm{dL}$ (female); anemia, $<14 \mathrm{~g} / \mathrm{dL}$ (male) and $<12 \mathrm{mg} / \mathrm{dL}$ (female); low albumin, $<3.5 \mathrm{mg} / \mathrm{dL} ;$ high CRP, $>0.5 \mathrm{mg} / \mathrm{dL}$. Univariate logistic regression analysis (adjusted for age) was used to investigate associations between mortality risk and clinical or laboratory parameters. LDH and age $\geq 70$ years were included as potential risk factors included in the univariate analysis. Multivariate logistic regression analysis was used to investigate the natures of associations between potential risk factors identified by univariate analysis and mortality. All tests were two-sided, 
and $p$-values of $<0.05$ were considered to indicate statistical significance. The analysis was conducted using the Statistical Package for Social Science Ver. 20.0 (SPSS, Chicago, IL, USA).

\subsection{Ethical Statement}

This study protocol was exempted from ethical review by the Institutional Review Board of Dongguk University Gyeongju Hospital because the data analyzed did not contain information that could be used to identify individual patients (IRB registration No. 110757-202006-HR-04-02).

\section{Results}

\subsection{Clinical Characteristics of the Study Subjects}

The baseline characteristics of the 324 study subjects are provided in Tables 1 and 2. Mean subject age was 55 years, and 55 had type 2 diabetes. The mean age in the diabetes group was greater than in the non-diabetes group (69.8 years vs. 51.9 years). The mortality rate in the diabetes group was remarkably higher than in the non-diabetes group ( $20.0 \%$ vs. $4.8 \%)$. Patients in the diabetes group stayed in hospital longer (22.8 vs. 18.5 days. $p=0.035)$ and had significantly higher comorbidity rates (e.g., hypertension, dyslipidemia, cardiovascular disease, and dementia) $(p<0.05)$. Chest radiology showed bilateral pneumonia was more common in the diabetes group (67.3\% vs. $43.1 \%)$. The laboratory findings showed blood glucose levels were higher and that AST or CRP elevation, anemia, and a low albumin level were more frequent in the diabetes group. Furthermore, more drugs were administered to patients with diabetes than to those without.

Table 1. General characteristics of the study subjects.

\begin{tabular}{|c|c|c|c|c|}
\hline Variables & Total Subjects & Diabetes & Non-Diabetes & $p$-Value \\
\hline Number of cases & 324 & 55 & 269 & \\
\hline Age, years & $55.0 \pm 21.4$ & $69.8 \pm 13.5$ & $51.9 \pm 21.4$ & $<0.001$ \\
\hline Body Mass Index, kg/m² & $23.7 \pm 4.4$ & $24.5 \pm 4.9$ & $23.5 \pm 4.3$ & 0.151 \\
\hline Systolic blood pressure, $\mathrm{mmHg}$ & $122.2 \pm 20.0$ & $127.5 \pm 25.2$ & $121.1 \pm 18.7$ & 0.032 \\
\hline Diastolic blood pressure, $\mathrm{mmHg}$ & $77.6 \pm 12.6$ & $79.5 \pm 16.2$ & $77.3 \pm 11.7$ & 0.241 \\
\hline Body temperature & $36.6 \pm 1.9$ & $36.7 \pm 0.9$ & $36.6 \pm 2.0$ & 0.787 \\
\hline Sex & & & & 0.454 \\
\hline Male & 135 (41.7) & $20(36.4)$ & $115(42.8)$ & \\
\hline Female & $189(58.3)$ & $35(63.6)$ & $154(57.2)$ & \\
\hline Current smoker & $55(17.0)$ & $11(20.0)$ & $44(16.4)$ & 0.554 \\
\hline Alcohol drinker & $52(16.0)$ & $10(18.2)$ & $42(15.6)$ & 0.687 \\
\hline Resident in care facility & $87(26.9)$ & $22(40.7)$ & $65(24.2)$ & 0.018 \\
\hline Days of hospitalization & $19.2 \pm 13.6$ & $22.8 \pm 18.1$ & $18.5 \pm 12.3$ & 0.035 \\
\hline Death & $24(7.4)$ & $11(20.0)$ & $13(4.8)$ & 0.001 \\
\hline \multicolumn{5}{|l|}{ Comorbidity } \\
\hline Hypertension & $80(24.7)$ & $32(58.2)$ & $48(17.8)$ & $<0.001$ \\
\hline Dyslipidemia & $25(7.7)$ & $9(16.4)$ & $16(5.9)$ & 0.022 \\
\hline Cardiovascular disease & $19(5.9)$ & $8(14.6)$ & $11(4.1)$ & 0.009 \\
\hline Cerebrovascular disease & $21(6.5)$ & $7(12.7)$ & $14(5.2)$ & 0.064 \\
\hline Dementia & $29(9.0)$ & $10(18.2)$ & $19(7.1)$ & 0.016 \\
\hline Malignancy & $13(4.0)$ & $3(5.5)$ & $10(3.7)$ & 0.469 \\
\hline \multicolumn{5}{|l|}{ Symptoms on admission } \\
\hline asymptomatic & $67(20.7)$ & $12(21.8)$ & $55(20.4)$ & 0.855 \\
\hline Cough & $105(32.4)$ & $10(18.2)$ & $95(35.3)$ & 0.017 \\
\hline Sputum & $57(17.6)$ & $8(14.5)$ & $49(18.2)$ & 0.697 \\
\hline Rhinorrhea & $12(3.7)$ & $2(3.6)$ & $10(3.7)$ & 0.999 \\
\hline Sore throat & $52(16.0)$ & $4(7.3)$ & $48(17.8)$ & 0.068 \\
\hline Dyspnea & $31(9.6)$ & $12(21.8)$ & $19(7.1)$ & 0.002 \\
\hline Gustatory dysfunction & $4(1.2)$ & 0 & $4(1.5)$ & 0.999 \\
\hline Olfactory dysfunction & $10(3.1)$ & 0 & $10(3.7)$ & 0.222 \\
\hline Febrile sense & $94(29.0)$ & $17(30.9)$ & $77(28.6)$ & 0.746 \\
\hline Headache & $42(13.0)$ & $5(9.1)$ & $37(13.8)$ & 0.508 \\
\hline Myalgia & $43(13.3)$ & $4(7.3)$ & $39(14.5)$ & 0.192 \\
\hline Fatigue & $16(4.9)$ & $3(5.5)$ & $13(4.8)$ & 0.741 \\
\hline Chest pain/discomfort & $25(7.7)$ & $5(9.1)$ & $20(7.4)$ & 0.591 \\
\hline Nausea/vomiting & $3(0.9)$ & $1(1.8)$ & $3(1.1)$ & 0.999 \\
\hline Diarrhea & $13(4.0)$ & $3(5.5)$ & $10(3.7)$ & 0.469 \\
\hline
\end{tabular}

Data are shown as mean \pm standard deviation or frequency (\%). $p$-value for differences between diabetes and non-diabetes. 
Table 2. Chest imaging findings, laboratory characteristics, and treatments.

\begin{tabular}{ccccc}
\hline Variables & Total Subjects & Diabetes & Non-Diabetes & $p$-Value \\
\hline Chest imaging & & & & 0.001 \\
None & $134(41.4)$ & $10(18.2)$ & $124(46.1)$ & \\
Bilateral infiltration & $153(47.2)$ & $37(67.3)$ & $116(43.1)$ & \\
Unilateral infiltration & $37(11.4)$ & $8(14.5)$ & $29(10.8)$ & \\
Laboratory findings & & & & \\
Blood glucose, mg/dL & $123.7 \pm 51.7$ & $189.1 \pm 90.0$ & $110.2 \pm 22.6$ & $<0.001$ \\
HbA1c, $\%$ & $7.27 \pm 1.89$ & $8.08 \pm 2.07$ & $6.14 \pm 0.69$ & 0.001 \\
Leukocyte, $>10.7 \times 10^{9} / \mathrm{L}$ & $29(5.9)$ & $5(9.1)$ & $14(5.2)$ & 0.339 \\
Lymphocyte, $<1.0 \times 10^{9} / \mathrm{L}$ & $62(19.1)$ & $15(27.3)$ & $47(17.5)$ & 0.131 \\
High Aspartate aminotransferase & $85(26.2)$ & $16(29.1)$ & $69(25.7)$ & 0.615 \\
High Alanine aminotransferase & $53(16.4)$ & $8(14.5)$ & $45(16.7)$ & 0.842 \\
High Lactate dehydrogenase & $62(19.1)$ & $19(34.5)$ & $43(16.0)$ & 0.003 \\
High Creatinine & $22(6.8)$ & $7(12.7)$ & $15(5.6)$ & 0.073 \\
Anemia & $72(22.2)$ & $21(38.2)$ & $51(19.0)$ & 0.004 \\
Albumin, <3.5 mg/dL & $30(9.3)$ & $11(20.0)$ & $19(7.1)$ & 0.008 \\
C-reactive protein, $>0.5 \mathrm{mg} / \mathrm{dL}$ & $152(53.1)$ & $41(74.5)$ & $111(41.3)$ & $<0.001$ \\
Treatments & & & & \\
Lopinavir/Ritonavir & $175(54.0)$ & $40(72.7)$ & $135(50.2)$ & 0.003 \\
Chloroquine & $54(16.7)$ & $17(30.9)$ & $37(13.8)$ & 0.005 \\
Antibiotics & $142(43.8)$ & $40(72.7)$ & $102(37.9)$ & $<0.001$ \\
Macrolide & $86(26.5)$ & $23(41.8)$ & $63(23.4)$ & 0.007 \\
Pegylated interferon- $\alpha$ & $56(17.3)$ & $16(29.1)$ & $40(14.9)$ & 0.018 \\
O2 supplement & $61(18.8)$ & $21(38.2)$ & $40(14.9)$ & $<0.001$
\end{tabular}

Results are presented as means \pm SDs or as frequency (\%). $p$-values are for differences between the diabetes and non-diabetes groups.

\subsection{Risk Factors of Mortality in COVID-19 Patients with Diabetes}

Univariate regression analysis showed an age of $\geq 70$ years and elevated LDH were significantly related to mortality in the diabetes group. However, other parameters including body mass index, smoking, alcohol drinking, leukocytosis, lymphopenia, glucose, and HbA1c were not significantly related to mortality (Table 3). Multivariate regression analysis showed an age of $\geq 70$ years and high LDH were significantly independent predictors of mortality among COVID-19 patients with diabetes (Table 4).

Table 3. Univariate regression analysis results for risk factors of mortality in COVID-19 patients with diabetes ${ }^{\text {a }}$.

\begin{tabular}{ccc}
\hline Variables & OR (95\%CI) & $p$-Value \\
\hline Age group, years & & \\
$\geq 70$ & $23.882(6.914-82.490)$ & $<0.001$ \\
Body Mass Index, $\mathrm{kg} / \mathrm{m}^{2}$ & $0.818(0.658-1.017)$ & 0.071 \\
Systolic blood pressure, $\mathrm{mmHg}$ & $0.989(0.959-1.019)$ & 0.458 \\
Diastolic blood pressure, $\mathrm{mmHg}$ & $0.984(0.938-1.033)$ & 0.518 \\
Body temperature, $\geq 37.5^{\circ} \mathrm{C}$ & $3.037(0.441-20.907)$ & 0.259 \\
Sex & & \\
Male & $0.948(0.130-6.922)$ & 0.958 \\
Female & & \\
Current smoker & $3.815(0.376-38.721)$ & 0.258 \\
Alcohol drinker & $0.931(0.075-11.483)$ & 0.955 \\
Resident in care facility & $0.572(0.087-3.766)$ & 0.572 \\
Comorbidity & $0.415(0.059-2.902)$ & 0.415 \\
Hypertension & $0.895(0.068-11.744)$ & 0.933 \\
Cardiovascular disease & $0.954(0.123-7.393)$ & 0.954 \\
Cerebrovascular disease & & \\
\hline
\end{tabular}


Table 3. Cont

\begin{tabular}{ccc}
\hline Variables & OR (95\%CI) & $p$-Value \\
\hline Dementia & $0.683(0.109-4.280)$ & 0.684 \\
Malignancy & $1.036(0.056-19.182)$ & 0.981 \\
Symptoms on admission & $1.736(0.267-11.299)$ & 0.564 \\
Dyspnea & $1.689(0.325-8.764)$ & 0.533 \\
Febrile sense & $1.509(0.075-30.184)$ & 0.788 \\
Diarrhea & & \\
Chest imaging & $4.682(0.429-51.019)$ & 0.205 \\
Bilateral infiltration & & \\
Laboratory findings & $0.996(0.985-1.008)$ & 0.547 \\
Blood glucose & $0.892(0.351-2.265)$ & 0.810 \\
HbA1c & $16.319(0.876-303.999)$ & 0.061 \\
Leukocyte, $>10.7 \times 10^{9} / \mathrm{L}$ & $4.375(0.800-23.937)$ & 0.089 \\
Lymphocyte, $<1.0 \times 10^{9} / \mathrm{L}$ & $2.888(0.490-17.014)$ & 0.241 \\
High Aspartate aminotransferase & $13.266(1.881-93.545)$ & 0.009 \\
High Lactate dehydrogenase & $1.807(0.216-15.115)$ & 0.585 \\
High Creatinine & $2.862(0.579-14.143)$ & 0.197 \\
Anemia & $2.464(0.426-14.261)$ & 0.314 \\
Albumin, <3.5 mg/dL & $2.004(0.604-16.946)$ & 0.256 \\
C-reactive protein &
\end{tabular}

${ }^{a}$ Adjusted for age. OR, odds ratio. CI, confidence interval.

Table 4. Multivariate regression analysis results for risk factors of mortality in COVID-19 patients with diabetes.

\begin{tabular}{ccc}
\hline Variables & OR (95\% CI) & $p$-Value \\
\hline$\geq 70$, year & $17.415(1.797-168.791)$ & 0.014 \\
High Lactate dehydrogenase & $9.703(1.812-51.961)$ & 0.008 \\
\hline
\end{tabular}

OR, odds ratio. $\mathrm{CI}$, confidence interval.

\section{Discussion}

In this era defined by the COVID-19 pandemic, early identification and reduction of mortality in those at risk population are essential, especially among COVID-19 patients with comorbid conditions, such as diabetes, cardiovascular disorders, renal diseases, and malignancies, to reduce mortality and minimize pain and suffering. This pandemic has suggested that the management of vulnerable populations might be successful when data-driven policies and strategies are adopted.

In the present study, we found that among 324 confirmed hospitalized patients with COVID-19, $55(16.97 \%)$ had diabetes mellitus, and that the mean age of patients with diabetes was greater than those without (69.8 years vs. 51.9 years). Notably, we found that the mortality rate was much higher among diabetic patients than in those without (20.0\% vs. $4.8 \%)$. Other authors have also reported higher rates of comorbid conditions such as cardiovascular, respiratory illnesses, chronic kidney diseases, malignancies, and diabetes mellitus in hospitalized COVID-19 patients [20-23], and diabetes was found to account for most of these comorbid conditions [24]. Moreover, the presence of diabetes in COVID-19 patients has been consistently reported to increase disease severity and the mortality risk $[25,26]$. A recent Chinese study reported that diabetes was an associated comorbidity in $14 \%$ of patients that survived COVID-19, but in 31\% of those that did not survive [25], and Shenoy et al., reported that the prevalence of diabetes was almost three times higher in COVID-19 patients with severe disease $(16.2 \%)$ than in those with non-severe disease (5.7\%) [26]. These findings suggest COVID-19 patients with diabetes should be prioritized and that focused preventive strategies be instituted to address diabetes and other associated comorbid conditions in order to reduce growing COVID-19 mortality and other poor health outcomes.

Interestingly, multivariate logistic regression analysis revealed that an age of $\geq 70$ years and a high serum LDH level significantly predicted mortality among hospitalized COVID-19 patients with 
diabetes. Similarly, other studies have reported that an age of $>60$ years is a major predictor of disease severity and mortality among diabetic COVID-19 patients [16,17]. A growing body of literatures supported an age of $\geq 70$ years' patients with COVID-19 had incremental severity and mortality than younger ones [23,27]. For example, a recent modeling study estimated that $20 \%$ of those aged 70 years or older patients with COIVD-19 were severe requiring hospitalization whereas only $<1 \%$ of those younger than 20 years needed so [23], while a Korean study reported that the age-specific death rate was the highest among patients over 70 years of age, with underlying diseases in their circulatory system [27]. Older individuals with diabetes mellitus and an acute respiratory illness are usually susceptible to develop complications such as severe acute respiratory syndrome (SARS), Middle East Respiratory Syndrome (MERS), influenza (including COVID-19), and thus, to be at higher risk of mortality [10]. Furthermore, it has been suggested that diabetic COVID-19 patients are more susceptible to an 'inflammatory storm', which is associated with rapid deterioration and high mortality risk [18].

As regards LDH levels, studies have reported poor clinical outcomes for patients with other viral infections when LDH levels are elevated, and as a result, LDH is considered an important biomarker of mortality [28,29]. In our study the cut-off value of LHD was set at 225 and 214 for male and female based on existing practices in South Korea in order to identify the associated risk for COVID-19 mortality. The differential in cut-off measurements might have varied reported results. Nonetheless, a meta-analysis identified significant differences between the LDH levels of COVID-19 patients with severe diseases and those without [30]. Likewise, another recent pooled analysis confirmed that LDH is positively associated with poorer outcomes in COVID-19 patients, and found that a high LDH level was associated with a 6-fold increase in the risk of developing severe disease and a 16-fold increase in mortality risk [31].

Our study findings should be interpreted in the light of certain specific limitations: First, identified predictors in Korean subjects might not be applicable to all human races. Second, the study was performed on a relatively small number of hospitalized COVID-19 patients at two hospitals, which may limit the generalizability of our findings to other settings. However, we believe that our results are meaningful as they should aid the development of customized preventive strategies aimed at reducing the burden of COVID-19. Additional large-scale studies are required to determine mortality and disease severity risks among hospitalized COVID-19 patients with other associated comorbid conditions.

\section{Conclusions}

In conclusion, our findings show that greater attention should be directed toward COVID-19 patients with diabetes older than 70 years and with those having an elevated LDH level to reduce the risk of mortality, and that focused preventive strategies be devised and implemented in this patient population. Further studies should be conducted in a large sample size in order to increase external validity and methods could rule out limitations inherent to this study.

Author Contributions: Conceptualization: D.S.L., K.L., S.-S.M.; Data curation: S.-S.M.; Formal analysis: S.-S.M.; Investigation: S.-S.M., Y.S.L.; Methodology: S.-S.M., Y.S.L.; Software: S.-S.M.; Validation: D.S.L., K.L., S.-S.M.; Writing—original draft: S.-S.M., D.A.; Writing—review and editing: D.S.L., K.L., D.A., S.-S.M.; All authors have read and agreed to the final version of the manuscript.

Funding: This research received no external funding.

Acknowledgments: The authors acknowledge the support of the Gyeongsangbuk-do Medical Association and the assistance of members of Gyeongsangbuk-do Center for Infectious Disease Control and Prevention. In addition, the authors extend special thanks to the staff of the Andong Medical Center for their generous assistance.

Conflicts of Interest: The authors declare no conflict of interest. 


\section{References}

1. World Health Organization. Coronavirus Disease (COVID-19) Situation Report-189; World Health Organization: Geneva, Switzerland, 2020.

2. Korean Ministry of Health and Welfare Cases in Korea. Available online: http://ncov.mohw.go.kr/ en/bdBoardList.do?brdId=16\&brdGubun=161\&dataGubun=\&ncvContSeq=\&contSeq=\&board_id= (accessed on 28 July 2020).

3. Barnes, M.; Sax, P.E. Challenges of "return to work" in an ongoing pandemic. N. Engl. J. Med. 2020, 383, 779-786. [CrossRef]

4. Zhang, Y.; Ma, Z.F. Impact of the COVID-19 pandemic on mental health and quality of life among local residents in Liaoning Province, China: A cross-sectional study. Int. J. Environ. Res. Public Health 2020, 17, 2381. [CrossRef] [PubMed]

5. Nguyen, H.C.; Nguyen, M.H.; Do, B.N.; Tran, C.Q.; Nguyen, T.T.; Khue, P.M.; Van, L.P.; Tran, K.V.; Duong, T.T.; Tran, T.V.; et al. People with suspected COVID-19 symptoms were more likely depressed and had lower health-related quality of Life: The potential benefit of health literacy. J. Clin. Med. 2020, 9, 965. [CrossRef] [PubMed]

6. Acter, T.; Uddin, N.; Das, J.; Akhter, A.; Choudhury, T.R.; Kim, S. Evolution of severe acute respiratory syndrome coronavirus 2 (SARS-CoV-2) as coronavirus disease 2019 (COVID-19) pandemic: A global health emergency. Sci. Total Environ. 2020, 730, 138996. [CrossRef] [PubMed]

7. Cheng, H.Y.; Jian, S.W.; Liu, D.P.; Ng, T.C.; Huang, W.T.; Lin, H.H. for the Taiwan COVID-19 outbreak investigation team. Contact tracing assessment of COVID-19 transmission dynamics in Taiwan and risk at different exposure periods before and after symptom onset. JAMA Intern. Med. 2020, 180, e202020. [CrossRef] [PubMed]

8. Peng, M. Outbreak of COVID-19: An emerging global pandemic threat. Biomed. Pharmacother. 2020, 129, 110499. [CrossRef] [PubMed]

9. Fan, J.; Liu, X.; Pan, W.; Douglas, M.W.; Bao, S. Epidemiology of coronavirus disease in Gansu Province, China, 2020. Emerg. Infect. Dis. 2020, 26, 1257-1265. [CrossRef]

10. Mazucanti, C.H.; Egan, J.M. SARS-CoV-2 disease severity and diabetes: Why the connection and what is to be done? Immun. Ageing 2020, 17, 1-11. [CrossRef]

11. Singh, A.K.; Khunti, K. Assessment of risk, severity, mortality, glycemic control and antidiabetic agents in patients with diabetes and COVID-19: A narrative review. Diabetes Res. Clin. Pr. 2020, 165, 108266. [CrossRef]

12. Ji, W.; Huh, K.; Kang, M.; Hong, J.; Bae, G.H.; Lee, R.; Na, Y.; Choi, H.; Gong, S.Y.; Choi, Y.H.; et al. Effect of underlying comorbidities on the infection and severity of COVID-19 in Korea: A nationwide case-control Study. J. Korean Med. Sci. 2020, 35, e237. [CrossRef]

13. Yang, X.; Yu, Y.; Xu, J.; Shu, H.; Xia, J.; Liu, H.; Wu, Y.; Zhang, L.; Yu, Z.; Fang, M.; et al. Clinical course and outcomes of critically ill patients with SARS-CoV-2 pneumonia in Wuhan, China: A single-centered, retrospective, observational study. Lancet Respir. Med. 2020, 8, 475-481. [CrossRef]

14. Shang, J.; Wang, Q.; Zhang, H.; Wang, X.; Wan, J.; Yan, Y.; Gao, Y.; Cheng, J.; Li, Z.; Lin, J. The relationship between diabetes mellitus and COVID-19 prognosis: A retrospective cohort study in Wuhan, China. Am. J. Med. 2020, S0002-9343, 30532-50002. [CrossRef] [PubMed]

15. Kumar, A.; Arora, A.; Sharma, P.; Anikhindi, S.A.; Bansal, N.; Singla, V.; Khare, S.; Srivastava, A. Is diabetes mellitus associated with mortality and severity of COVID-19? A meta-analysis. Diabetes Metab. Syndr. Clin. Res. Rev. 2020, 14, 535-545. [CrossRef]

16. Mantovani, A.; Byrne, C.D.; Zheng, M.H.; Targher, G. Diabetes as a risk factor for greater COVID-19 severity and in-hospital death: A meta-analysis of observational studies. Nutr. Metab. Cardiovasc. Dis. 2020, 30, 1236-1248. [CrossRef] [PubMed]

17. Chung, S.M.; Lee, Y.Y.; Ha, E.; Yoon, J.S.; Won, K.C.; Lee, H.W.; Hur, J.; Hong, K.S.; Jang, J.G.; Jin, H.J.; et al. The risk of diabetes on clinical outcomes in patients with coronavirus disease 2019: A retrospective cohort study. Diabetes Metab. J. 2020, 44, 405-413. [CrossRef]

18. Guo, W.; Li, M.; Dong, Y.; Zhou, H.; Zhang, Z.; Tian, C.; Qin, R.; Wang, H.; Shen, Y.; Du, K.; et al. Diabetes is a risk factor for the progression and prognosis of COVID-19. Diabetes Metab. Res. Rev. 2020, e3319. [CrossRef] 
19. Liu, Z.; Li, J.; Huang, J.; Guo, L.; Gao, R.; Luo, K.; Zeng, G.; Zhang, T.; Yi, M.; Huang, Y.; et al. Association between diabetes and COVID-19: A retrospective observational study with a large sample of 1,880 cases in Leishenshan Hospital, Wuhan. Front. Endocrinol. 2020, 11, 478. [CrossRef]

20. Wang, D.; Hu, B.; Hu, C.; Zhu, F.; Liu, X.; Zhang, J.; Wang, B.; Xiang, H.; Cheng, Z.; Xiong, Y.; et al. Clinical characteristics of 138 hospitalized patients with 2019 novel coronavirus-infected Pneumonia in Wuhan, China. JAMA 2020, 323, 1061-1069. [CrossRef]

21. Liu, J.; Zhang, S.; Wu, Z.; Shang, Y.; Dong, X.; Li, G.; Zhang, L.; Chen, Y.; Ye, X.; Du, H.; et al. Clinical outcomes of COVID-19 in Wuhan, China: A large cohort study. Ann. Intensiv. Care 2020, 10, 99. [CrossRef]

22. Guan, W.J.; Ni, Z.Y.; Hu, Y.; Liang, W.H.; Ou, C.Q.; He, J.X.; Liu, L.; Shan, H.; Lei, C.L.; Hui, D.S.; et al. Clinical characteristics of coronavirus disease 2019 in China. N. Engl. J. Med. 2020, 382, 1708-1720. [CrossRef]

23. Clark, A.; Jit, M.; Warren-Gash, C.; Guthrie, B.; Wang, H.H.X.; Mercer, S.W.; Sanderson, C.; McKee, M.; Troeger, C.; Ong, K.L.; et al. Global, regional, and national estimates of the population at increased risk of severe COVID-19 due to underlying health conditions in 2020: A modelling study. Lancet Glob. Health 2020, 8, e1003-e1017. [CrossRef]

24. Emami, A.; Javanmardi, F.; Pirbonyeh, N.; Akbari, A. Prevalence of underlying diseases in hospitalized patients with COVID-19: A systematic review and meta-analysis. Arch. Acad. Emerg. Med. 2020, 8, e35. [PubMed]

25. Zhou, F.; Yu, T.; Du, R.; Fan, G.; Liu, Y.; Liu, Z.; Xiang, J.; Wang, Y.; Song, B.; Gu, X.; et al. Clinical course and risk factors for mortality of adult inpatients with COVID-19 in Wuhan, China: A retrospective cohort study. Lancet 2020, 395, 1054-1062. [CrossRef]

26. Shenoy, A.; Ismaily, M.; Bajaj, M. Diabetes and covid-19: A global health challenge. BMJ Open Diabetes Res. Care 2020, 8, e001450. [CrossRef] [PubMed]

27. Kang, Y.J. Mortality rate of infection with COVID-19 in Korea from the perspective of underlying disease. Disaster Med. Public Health Prep. 2020, 1-3. [CrossRef]

28. Chiang, C.; Shih, J.F.; Su, W.J.; Perng, R.P. Eight-month prospective study of 14 patients with hospital-acquired severe acute respiratory syndrome. Mayo Clin. Proc. 2004, 79, 1372-1379. [CrossRef]

29. Tao, R.J.; Luo, X.L.; Xu, W.; Mao, B.; Dai, R.X.; Li, C.W.; Yu, L.; Gu, F.; Liang, S.; Lu, H.W.; et al. Viral infection in community acquired pneumonia patients with fever: A prospective observational study. J. Thorac. Dis. 2018, 10, 4387-4395. [CrossRef]

30. Henry, B.M.; De Oliveira, M.H.S.; Benoit, S.; Plebani, M.; Lippi, G. Hematologic, biochemical and immune biomarker abnormalities associated with severe illness and mortality in coronavirus disease 2019 (COVID-19): A meta-analysis. Clin. Chem. Lab. Med. 2020, 58, 1021-1028. [CrossRef]

31. Henry, B.M.; Aggarwal, G.; Wong, J.; Benoit, S.; Vikse, J.; Plebani, M.; Lippi, G. Lactate dehydrogenase levels predict coronavirus disease 2019 (COVID-19) severity and mortality: A pooled analysis. Am. J. Emerg. Med. 2020, 38, 1722-1726. [CrossRef]

(C) 2020 by the authors. Licensee MDPI, Basel, Switzerland. This article is an open access article distributed under the terms and conditions of the Creative Commons Attribution (CC BY) license (http://creativecommons.org/licenses/by/4.0/). 